ORIGINAL ARTICLE

\title{
Isolation and Identification of Microbes on Hands and Mobile Phones Causing Urinary Tract Infections
}

\author{
Anum Liaquat Ali, Umrah Imran, Mehwish Sajjad, Hhira Waseem, Tanzela Khan, Sikandar Ali, Sidra Afzal, Afsheen Khan, \\ Tahira, Bushra Imdad \\ Department of Clinical Laboratory Sciences (CLS), Dow Institute of medical Technology (DIMT), \\ Dow University of Health Sciences (DUHS), Karachi, Pakistan.
}

\begin{abstract}
Background: Hands and cell phones are the major source of cross-transmission of urinary tract infections. The aim of this study was to isolate, identify and evaluate Gram-negative bacteria from hand and mobile phones.

Methods: This study was conducted in visiting area of Civil Hospital Karachi, Pakistan. Analysis was done by 100 wet sterile cotton tipped swabs, 50 each from mobile phones and hands of their owners. Samples were transported in a Cary Blair transport media, Swabs were streaked on Nutrient agar, Blood agar and MacConkey agar. Organisms were identified by cultural, biochemical, and microscopic characteristics.

Results: Total samples $n=100$ was collected from hand and mobile phones samples ( 50 hand and 50 mobile swabs) from the Dow university Hospital and Civil Hospital Karachi were tested. Six species of bacteria were isolated along with their identification during the research study. The isolated bacteria were Serratia, Klebsiella, Pseudomonas, Proteus, Shigella and Escherichia coli. The participants' hands showed high bacterial contamination (50\%-56\%) in comparison to mobile phones. The frequency (\%) of bacteria isolated from mobile phone and hand swabs included Serratia, $12(24 \%)$ with the highest quantity and frequently found bacteria. While, the rest of the results reported Escherichia coli 10 (20\%), Klebsiella 9 (18\%), Pseudomonas 5 (10\%), Shigella $4(8 \%)$ and Proteus $10(20 \%)$ respectively.
\end{abstract}

Conclusion: Patient attendants in hospitals and visitors are more susceptible to nosocomial infections through exchange of mobile phones $n=12(24 \%)$. Therefore, hygienic practice of hands cleaning while mobile using may help to break the transmission cycle of pathogenic bacteria.

Keywords: Urinary Tract Infections; Gram Negative Bacteria; Nosocomial Infections.

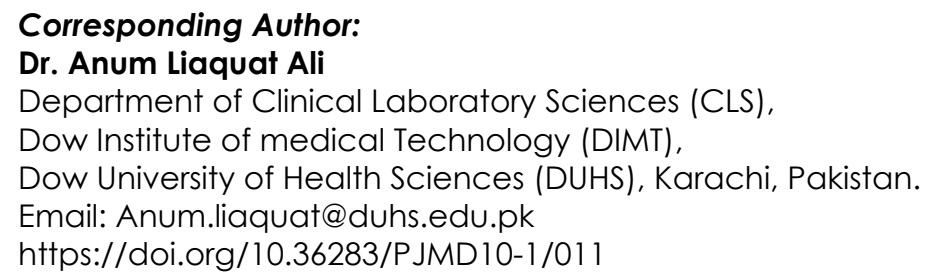

\section{INTRODUCTION}

It is an indisputable fact that infectious diseases are increasing day-by-day. In poor countries, peoples of over $25 \%$ suffer from nosocomial infections. On the other hand, around 100,000 fatalities occur in U.S. hospitals, as they are responsible for 1.7 million infections. It is certainly true that standard infection control instructions would be useful against one-third of such infections ${ }^{1,2}$. Urinary Tract Infections (UTIs) identification by bacterial test susceptibility, is significant for selecting suitable antimicrobial agent distressing bacterial diseases ${ }^{3}$.

The cellular appliance has become one of the most crucial supplements of executive and communal life undoubtedly; it has made a tremendous impact on our lives in this rapidly changing world. It is used 
as a fundamental source of communication by affluent societies low-income earners ${ }^{4}$. Mobile phone regularly became new and more complicated in daily life, together with classified and related work capacity With the high rang of mobile phone ${ }^{5}$.

Gram-positive bacteria which are related to individuals produced through organisms Gram-negative and generally include urinary frequency, or suprapubic pain, dysuria, urinary urgency ${ }^{6,7}$. The increase use of cephalosporin is responsible for the production highly resistance of Extended-spectrum beta-lactamases (ESBL) microorganisms ${ }^{8}$. These organisms are ubiquitous and find their way into the phones through the skin. This is an inevitability that some bacteria are part of the normal flora of the skin $^{10}$. All microbiologists state that grouping of continuous handling by the phones creates a prime breeding ground for many microorganisms ${ }^{11}$.

Hands and mobiles are thought to be a great source of infection that is why they were chosen for the collection of samples. Civil hospital is in the working area of city; the roads around it are always busy with traffic. As people keep their cell phones with them, their cell phones get exposure to the polluted environment. In addition, it is among the largest and economical hospitals of Karachi, for this reason it is preferred by a vast majority of people. Mostly socioeconomic people come here as they are served at a very low cost. However, unfortunately, sanitary rules are not applied here. The lack of availability of cleaning guidelines led to nosocomial infections simply. Hands act as a route of transmission of several infections as UTI. Many people show idleness in washing hands. A very few people are aware of the sanitary practices. Even medical staff show carelessness and treat patients with contaminated hands. As patients are already immuno-compromised, they are more prone to get infection easily ${ }^{12-14}$.

The Gram-negative rods isolated from hands and mobile phones, are all responsible for urinary tract infections. Unluckily, in a country like Pakistan, personal hygienic rules are not followed. A common example is hastiness in washing hands after using washroom. The organisms like (E. coli, Klebsiella, Serratia, Proteus, Pseudomonas and Shigella) are transmitted from hands to mobiles and vice versa ${ }^{15-17}$. They are responsible for many infectious diseases like UTI (urinary tract infection) ${ }^{17}$. Their presence in samples might be due to the mobile phones are used routinely all day long but not cleaned properly. People may do not wash their hands as often as they should. This study aimed to evaluate the role of mobile phones and hands in the transmission of bacteria.

\section{METHODS}

The study was conducted at Dow University of Health Sciences, Karachi. The samples were collected from Dow University of health sciences Karachi and Civil hospital Karachi. Informed consent was taken from the participant included in the study. The research was conducted after approval from the ethics review committee of the Institution of biological, biochemical, and pharmaceutical sciences (IBBPS) (Ref. No. IBBPS/UL/R\&DM-003). The samples were collected aseptically with wet sterile cotton swab sticks dipped in Cary Blair transport media.

Total samples 100 were collected from hand and mobile phones, 50 samples collected from the Dow University Hospital (25 hands and 25 mobile) and 50 samples collected from Civil Hospital Karachi (25 hands and 25 mobile). Each swab was streaked on nutrient, blood, and MacConkey agar. The plates were incubated at $37^{\circ} \mathrm{C}$ for 48 hours and observed for colonial characteristics. Bacteria were identified by their morphological and biochemical characteristics ${ }^{18}$. Gram staining was done for further recognition $^{19}$.

Biochemical reactions were done to verify each bacterial isolate by doing Triple Sugar Iron TSI, Citrate and Oxidase for the identification of Gram-negative bacteria ${ }^{19}$. A total of 25 samples were collected from cell phones, out of which 3 samples were positive. In this research, total samples 100 from hands 50 samples and cell phones 50 samples were collected from persons having age between 28 to 43 all result were analysis SPSS

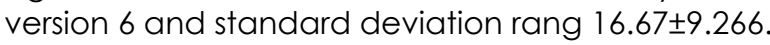

\section{RESULTS}

Total samples 100 were collected from hand and mobile phones, from which six species of bacteria: Serratia, Klebsiella, Pseudomonas, Proteus, Shigella, and Escherichia coli. were isolated. The participants' hands showed high bacterial contamination other than mobile phones. Thirty-eight were males and 12 were females. The frequency of bacteria isolated from mobile phone and hand swabs from both hospitals are shown in Table 1. 
Table 1: Univariate analysis of factors associated with hand and mobile contamination between Dow University Hospital and Ruth Pfau Civil Hospital, Karachi.

\begin{tabular}{|c|c|c|c|c|c|c|c|}
\hline \multirow{2}{*}{ Parameters } & \multicolumn{2}{|c|}{ Hands } & \multirow{2}{*}{ p-Value } & \multicolumn{2}{|c|}{ Mobiles } & \multirow{2}{*}{$p$-Value } & \multirow{2}{*}{ Tota } \\
\hline & Positive & Negative & & Positive & Negative & & \\
\hline Male & $15(39 \%)$ & $5(13 \%)$ & \multirow{2}{*}{1.000} & $15(39 \%)$ & $3(7.8 \%)$ & \multirow{2}{*}{1.000} & 38 \\
\hline Female & $6(50 \%)$ & $1(8.3 \%)$ & & $4(33.3 \%)$ & $1(8.3 \%)$ & & 12 \\
\hline DUH & $25(50 \%)$ & $5(10 \%)$ & \multirow{2}{*}{1.000} & $15(30 \%)$ & $5(10 \%)$ & \multirow{2}{*}{0.416} & 50 \\
\hline CHK & $28(56 \%)$ & $5(10 \%)$ & & $15(30 \%)$ & $2(4 \%)$ & & 50 \\
\hline
\end{tabular}

Serratia, 12(24\%) was the most frequent bacteria isolated (Table 2) followed by Escherichia coli 10

(20\%), Klebsiella 9(18\%), Pseudomonas 5(10\%), Shigella $4(8 \%)$, Proteus $10(20 \%)$.

Table 2: Bacterial species isolated from the hand and mobile phone from Dow University Hospital and Civil Hospital.

\begin{tabular}{|l|c|c|c|c|c|}
\hline \multirow{2}{*}{ Bacteria } & \multicolumn{2}{|c|}{ Dow University Hospital } & \multicolumn{2}{c|}{ Civil Hospital } & \multirow{2}{*}{$\begin{array}{c}\text { Frequency } \\
\text { Percentage } \mathbf{n}(\%)\end{array}$} \\
\cline { 2 - 5 } & Hand & Mobile & Hand & Mobile & $12(24)$ \\
\hline Serratia & 5 & 1 & 5 & 1 & $10(20)$ \\
\hline E. coli & 5 & 1 & 4 & 0 & $9(18)$ \\
\hline Klebsiella & 4 & 1 & 3 & 1 & $5(10)$ \\
\hline Pseudomonas & 2 & 1 & 2 & 0 & $4(8)$ \\
\hline Proteus & 6 & 1 & 3 & 0 & $10(20)$ \\
\hline Shigella & 2 & 0 & 2 & 0 & \\
\hline
\end{tabular}

E. coli was detected in hands among nine individuals and cell phones of one participant having urine infection shown in Figure 1a. Only one had E. coli in his cell phone. Serratia was detected in hands among ten and phones of two people had a history of urine infection. Hands of two samples were contaminated with Serratia, however their cellular device showed no bacterial contamination. Shigella was isolated only in hands of 10 participants having diarrhea. Hands of seven participants and cell phones of two respondents with urine infection showed colony of Klebsiella while only cell phone of one participant attendant had a growth of Klebsiella reported in this research study. Hands and cell phones of females with vaginal infection showed growth of Proteus among ten as shown in Figure $1 \mathrm{~b}$ and Pseudomonas among five participants reported in results.
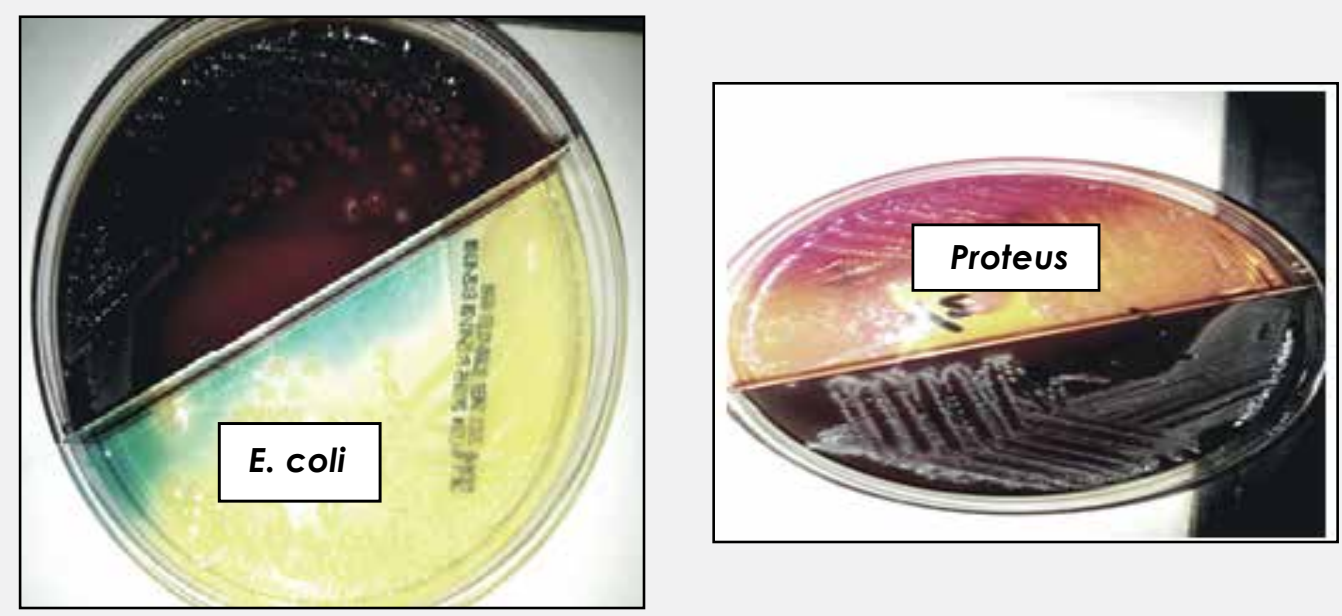

Figure 1a: Isolation of E. coli in Agar Plate. 1b: Proteus species isolated in Agar Plate. 


\section{DISCUSSION}

In this current study total 6 different species of bacteria were isolated which were from the DUH and CHK isolated samples of mobile phones and hands. Therefore, total mobile phone percentage was $4 \%$ and hands percentage was about $20 \%$. According to past literature, numerous species of bacteria are considered of pathogens in human, as Serratia, E. coli, Klebsiella, Shigella, Proteus, and Pseudomonas. These bacterial species can cause severe diseases including the urinary tract infections. Nosocomial infections continue to pose risks of increased mortality and morbidity rate in patients. The hands of healthcare workers (HCWs) play an important role in transmission of infections ${ }^{8}$. The mobile phones of HCWs have seen many harmful pathogens, which act as a pool for nosocomial infections ${ }^{20,21}$. Thus, the etiological agents of nosocomial infections have found a significant way to spread in our hospitals. Mobile phones appear in direct touch with the hands, face, and act as a prepared site to inhabit various microbes ${ }^{21}$.

Klebsiella, a Gram-negative bacteria, member of family Enterobacteriaceae, is a normal flora of human mouth, skin and intestine ${ }^{22}$. Therefore, this study related results also showed this bacterium which was present in hands even more than the mobile phones. Since, people touch their body parts and then use their mobile phones with contaminated hands. For that reason, our study also showed gram negative bacteria. To the best of our knowledge, E. coli is another Gram-negative bacterium, which is a part of normal flora of lower intestine. It causes diseases like diarrhea, abdominal cramping, and nausea. It reaches our food through contaminated hand as its route is fecal-oral ${ }^{23,24}$. This research also showed $E$. coli which is more commonly present in hands than on the mobile phones.

Serratia is another Gram-negative rod-shaped bacterium from a family Enterobacteriaceae and the most common specie in this genus is $S$. marcescens. It causes nosocomial infections as it has a propensity to populate the respiratory, urinary tracts, and causes infection of eyes, blood, and wounds. It can transfer by contaminated or infectious people, medical devices, and direct contact to mucous membrane 25,26 .

Serratia is also found in plants and animals. As it is very common, here that people pluck flower and leaves, touch domestic animals, and do not wash their hands. Therefore, in this way Serratia causes contamination of hands. Serratia infections are related to hospitalization, likewise, invasive procedure such as intravenous catheterization, respiratory intubation and urinary tract manipulation also contributes in these aspects ${ }^{27}$. This research also goes in the favor of our research study since, Serratia also present more common in hands than on mobiles phones which has confirmed by our research as well.

Pseudomonas causes urinary tract infections and our results also reported the presence of this bacterial infection. It can cause pneumonia, diarrhea, enterocolitis, enteritis, meningitis etc. It contaminates respiratory therapy and anesthesia equipment, intravenous fluids and even distilled water. It also has a capability to survive in disinfectants, as it grows in hexa-chloroform containing soap solution, in antiseptics and in detergents ${ }^{28}$. Our study also supported its presence in hands more as compared to the cell phones. Its presence in wound site causes contamination of hands when a person itches that site. The four Fs, fingers, flies, food and feces by contaminated water and polluted environment normally transmit Shigella ${ }^{28}$. Our study has also revealed the presence of Shigella more in hand than on mobile phones. However, past research reported that Proteus species are the root of hospital-acquired infections, for instance, urinary tract, wounds and burns etc ${ }^{29}$. Within the context of the European region, Proteus species are the second most commonly isolated bacteria after the $E$. coli ${ }^{29,30}$.

Hence, we are exposed to these types of organisms, which are very harmful for us. The most critical place for patients is hospital where numerous microbes show their presence. Microbiological standards in hygiene are obligatory for a healthy life, especially people present in hospitals, since visitors are very incautious about their hygiene. They do not wash their hands properly and then use their mobile phones with contaminated hands. Therefore, organisms are transferred from hands to mobiles and infections occur when that contaminated mobile is used. The major visitors should take preventive effort is hand washing, so the bacteria will not transfer from their hands to mobiles. Awareness programs should be started as well so that the people can realize how to care themselves while present in a hospital. Infections can be restricted by taking preventive steps. Thus, we can easily avoid spreading bacterial infection just by using regular cleansing agent and rearranging our environment.

\section{CONCLUSION}

Hands and mobile phones are vehicles of transmission of infectious diseases due to the nullifying of sanitary rules. Strict health hygiene should be practiced for prevention. Hands should be properly washed. Developing active preventive strategies like routine decontamination of mobile phones with alcohol containing disinfectant material might be effective in reducing cross infection. Another way to reduce bacterial contamination on mobile phones might be the use of antimicrobial additive materials. 


\section{ACKNOWLEDGEMENTS}

We are immensely grateful to the patients and their guardians who allowed us to collect samples from their hands and mobile phones.

\section{CONFLICT OF INTEREST}

The authors declare no conflict of interest.

\section{ETHICS APPROVAL}

The research was conducted after receiving approval from IBBPS (Institutional of biological, biochemical, and pharmaceutical sciences) (Ref. No. IBBPS/UL/R\&DM-003).

\section{PATIENT CONSENT}

The authors obtained both written and verbal consent from the participants involved in this study.

\section{FUNDING}

The authors received funding for this research from Dow Institute of Medical Technology (Dow University of Health Sciences).

\section{AUTHORS' CONTRIBUTION}

This study was directed and supervised by NHA; ALA had a major role in collection, analysis, and interpretation of data. UI and the rest of the authors assisted in manuscript writing. All authors read and approved the final manuscript.

\section{REFERENCES}

1. Mayhall CG. Hospital epidemiology and infection control. Lippincott Williams \& Wilkins; 2012.p.1-4. 2. Khan HA, Baig FK, Mehboob R. Nosocomial infections: Epidemiology, prevention, control and surveillance. Asian Pac J Trop Biomed. 2017;7(5):478-482. 3. Salih MK, Alrabadi NI, Thalij KM, Hussien AS. Isolation of path4ogenic gram-negative bacteria from urinary tract infected patients. Open J Med Microbiol. 2016;6(02):59-65.

4. Marchaim D, Kaye K. Infections and antimicrobial resistance in the intensive care unit: epidemiology and prevention 2019 [Internet]. Prieiga per interneta, 2019 [cited $2020 \mathrm{Sep}$ 18]. Available from: https://www. uptodate. com/contents/infectionsand-antimicrobial-resistance-in-the-intensivecare-unit-epidemiology-and-prevention.

5. Mohammed TK, Jwad MA, Kamal O, Abbas AH, Alabbas AS. Isolation of some pathogenic bacteria and fungi from students mobile phones (Part I). Indian J Public Health Res Dev. 2019;10(10):2108-21 12.

6. Kline KA, Lewis AL. Gram-positive uropathogens, polymicrobial urinary tract infection, and the emerg- ing microbiota of the urinary tract. Urin Tract Infect Mol Pathogen Clin Manag. 2017:459-502.

7. Zowawi HM, Harris PN, Roberts MJ, Tambyah PA, Schembri MA, Pezzani MD, et al. The emerging threat of multidrug-resistant Gram-negative bacteria in urology. Nat Rev Urol. 2015;12(10): 570-584. 8. Sharma BK, Sharma K. Extended spectrum $\beta$-lactamase producers in mobile phones and nosocomial infections: Risk factors for infection control practices. Janapriya J Interdiscip Stud. 2019:8:60-74.

9. Acalovschi M, Badea R, Dumitrascu D, Varga C. Prevalence of gallstones in liver cirrhosis: A sonographic survey. Am J Gastroenterol. 1988;83(9): 954-956.

10. Esmaeili Z, Sadeghi J, Razavi S, Oshaghi M, Sayyahfar S, Rahbar $M$, et al. High level of biofilm formation and virulence factors in enterococci species isolated from clinical and normal flora samples. Infect Dis Clin Pract. 2018;26(1):27-30.

11. Kadhem $\mathrm{H}$, Abed Ali A, Hassan O. Isolation and identification of bacteria isolated from different parts of cell phones. World J Exp Biosci. 2016;4(1):29-31.

12. Rathore $M H$, Jackson MA, Committee on Infectious Diseases. Infection prevention and control in pediatric ambulatory settings. Pediatr. 2017;140(5): 1-25.

13. Johnson CO, Nguyen $M$, Roth GA, Nichols $E$, Alam T, Abate D, et al. Global, regional, and national burden of stroke, 1990-2016: a systematic analysis for the Global Burden of Disease Study 2016. Lancet Neurol. 2019;18(5):439-458.

14. Jenkins DR. Nosocomial infections and infection control. Med. 2017;45(10):629-633.

15. Aguado J, Silva J, Fernandez-Ruiz M, Cordero E, Fortún J, Gudiol C, et al. Management of multidrug resistant Gram-negative bacilli infections in solid organ transplant recipients: SET/GESITRA-SEIMC/REIPI recommendations. Transplant Rev. 2018;32(1):36-57. 16. Presterl E, Diab-El Schahawi M, Lusignani LS, Paula H, Reilly JS. Bacteriology: Selected bacteria and diseases. Basic microbiology and infection control for midwives: Springer; 2019. p.67-84.

17. Alatoom A, Elsayed H, Lawlor K, AbdelWareth L, El-Lababidi R, Cardona $L$, et al. Comparison of antimicrobial activity between ceftolozane-tazobactam and ceftazidime-avibactam against multidrug-resistant isolates of Escherichia coli, Klebsiella pneumoniae, and Pseudomonas aeruginosa. Int J Infect Dis. 2017;62:39-43.

18. Azizah RA. Physical characteristics and antibacterial activities of onion cream ethanol extract (Eleutherine palmifolia) (Against Staphylococcus aureus) [dissertation]. University of Muhammadiyah Malang); 2019.80.

19. Cheesbrough M. District laboratory practice in tropical countries, part 2. Cambridge university press; 2006. p. 1-15.

20. Miller MA, Hyland $M$, Ofner-Agostini $M$, Gourdeau M. Ishak M. Morbidity, mortality, and healthcare burden of nosocomial Clostridium difficile-associated diarrhea in Canadian hospitals. Infect Control Hosp Epidemiol. 2002;23(3):137-140. 
21. Mark D, Leonard C, Breen H, Graydon R, O'Gorman C, Kirk S. Mobile phones in clinical practice: reducing the risk of bacterial contamination. Int J Clin Pract. 2014;68(9):1060-1064.

22. Schulz-Stübner S, Kniehl E. Transmission of extended-spectrum $\beta$-lactamase Klebsiella oxytoca via the breathing circuit of a transport ventilator: root cause analysis and infection control recommendations. I Infect Control Hosp Epidemiol. 2011 ;32(8):828-829.

23. Al-Abdalall $\mathrm{AH}$. Isolation and identification of microbes associated with mobile phones in Dammam in eastern Saudi Arabia. J Fam Med Community Med. 2010;17(1):11-14.

24. Nwankwo E, Ekwunife N, Mofolorunsho K. Nosocomial pathogens associated with the mobile phones of healthcare workers in a hospital in Anyigba, Kogi state, Nigeria. J Epidemiol Glob Health. 2014;4(2):135-140.

25. Rabier V, Bataillon S, Jolivet-Gougeon A, Chapplain JM, Beuchée A, Bétrémieux P. Hand washing soap as a source of neonatal Serratia marcescens outbreak. Acta Paediatrica. 2008;97(10):1381-1385. 26. Pitout JD, Sanders CC, Sanders Jr WE. Antimicrobial resistance with focus on $\beta$-lactam resistance in gram-negative bacilli. Am J Med. 1997;103(1):51-59. 27. Rusin P, Maxwell S, Gerba C. Comparative surface-to-hand and fingertip-to-mouth transfer efficiency of gram-positive bacteria, gram-negative bacteria, and phage. J Appl Microbiol. 2002; 93(4):585-592.

28. Brooks G, Carroll K, Butel J, Morse S, Mietzner T. Jawetz, Melnick, Adelberg Medical Microbiology, twenty-sixth American edition / first Croatian edition.

29. O'Hara CM, Brenner FW, Miller JM. Classification, identification, and clinical significance of Proteus, Providencia, and Morganella. Clin Microbiol Rev. 2000;13(4):534-546.

30. Liu P, Gur D, Hall LM, Livermore D. Survey of the prevalence of Blactamases amongst 1000 Gramnegative bacilli isolated consecutively at the Royal London Hospital. J Antimicrob Chemother. 1992;30 (4):429-447 